\title{
Revalorización de los sofistas
}

DOI: http://dx.doi.org/10.5377/koot.v0i10.6698

URI: http://hdl.handle.net/11298/784

\author{
Héctor Samour \\ Docente investigador \\ Universidad Centroamericana José Simeón Cañas, UCA \\ hsamour@uca.edu.sv
}

\section{Resumen}

El artículo hace una revisión minuciosa en torno al pensamiento de los sofistas, con el fin de mostrar que su filosofía constituye uno de los momentos claves de la historia de la filosofía griega. Lejos de ser un grupo de pensadores superficiales con un absurdo afán de destruir todo fundamento de una auténtica filosofía, los sofistas aparecen como los iniciadores de un giro decisivo en la historia del pensamiento humano, que puso en primer plano los problemas de la vida social y ética, junto con el esclarecimiento de lo que fuesen las leyes y las normas morales, así como de la inserción del ser humano en su medio histórico y natural.

Palabras claves: Filosofía griega, sofistas, Platón, ética.

\begin{abstract}
The article makes a comprehensive review of the thoughts of the sophists, to show that their philosophy constitutes one of the key moments in the history of Greek philosophy. Far from being a group of superficial thinkers with an absurd desire to destroy any foundation of a true philosophy, the sophists appear as the initiators of a decisive turn in the history of human thought, which put in the foreground the problems of the social and ethical life, together with the clarification of what the laws and the moral norms were, as well as the insertion of the human being in its historical and natural environment.
\end{abstract}

Keywords: Greek philosophy, Sophists, Plato, Ethics. 
1. Hablar de los sofistas presenta dificultades de varios tipos: de tipo técnico y metodológico unas, e ideológico otras. Las dificultades de tipo técnico son las mismas que cuando se estudia a cualquier presocrático: sólo se disponen de fragmentos de sus obras, por lo que la reconstrucción de su pensamiento mediante de exposiciones o textos, que a veces se encuentran en testimonios que no merecen confianza, resulta difícil. Si nos quedamos interpretando sólo los fragmentos, que sería lo más objetivo, nos quedaríamos con una imagen muy pobre.

Pero no solamente son dificultades técnicas, sino que a veces el problema es ideológico. La principal fuente de interpretación de los sofistas es la de Platón. Pero la interpretación de Platón es interesada, ya que, al hacerla, tenía más interés en justificar su propio sistema y el que atribuía a Sócrates, que en dar una visión objetiva de la enseñanza de éstos. Lo que significa que el mejor testimonio que se tiene no es excesivamente fiable. Además, ha habido toda una tradición filosófica que, al mismo tiempo que exaltaba las doctrinas platónicas, denostaba a sus oponentes.

Si obviamos esto, se podría decir que los sofistas dan inicio a lo que llamaríamos "ciencias sociales". Aunque hay alusiones en los presocráticos a temas de filosofía política, ésta no es precisamente su característica principal, y, por lo tanto, la consideración racional más explícita de estos temas lo dan los sofistas: El estudio de las leyes, los estudios de gramática y retórica y el concepto de educación, son propios de la sofística y ajenos a la filosofía de la naturaleza precedente.

Además, la teoría del conocimiento de los sofistas surge como una crítica de las investigaciones de la naturaleza y de la ontología montada sobre ella, pero éstos no se quedan en mera crítica. Sus investigaciones sobre la vida social les proporcionan una manera distinta de enfocar el problema del conocimiento, lo mismo que una nueva manera de enfocar al hombre y el mundo, el tipo de saber sobre lo que reflexionan también lo es y además, porque la función de ese ser tiene una vertiente práctica fundamental. Su valoración depende de su repercusión social y política y no sólo su valor teórico contemplativo.

2. Para iniciar la revalorización de los sofistas, diremos que las palabras "sofista" y "sofística" tienen una historia que es conveniente conocer. Sofistés (sofistas) es una palabra derivada del adjetivo sofos (sabio) y directamente del verbo sofinonai (idear, inventar), que originalmente designaba a toda persona que ha llegado a destacarse en alguna clase de actividad. Entonces, originalmente, sofía y sofós tenían el significado más traducible por "destreza", "diestro" en una ocupación determinada; posteriormente, el significado evolucionó hacia un significado relacionado con el conocimiento, con lo que pasó a denotar algo 
próximo a la verdad de quien mereciera ese calificativo. Así, por ejemplo, Píndaro podía escribir que el sabio es el que conoce más por naturaleza. Esquilo, que el que tiene un conocimiento útil es sabio, no el que tiene muchos conocimientos. Por su parte, la palabra sofistés (sofista), es un nombre derivado del verbo sofistestai - practicar sofía. Diógenes Laercio puso de manifiesto que, en principio, sofós y sofistés eran sinónimos. El término implicaba la idea de educación y se aplicaba a los grandes poetas, considerados en Grecia como los grandes educadores. El sofista enseña porque tiene un conocimiento o una destreza especial que impartir, ya sea en las artes técnicas, en la oral o en la política. Su sofía es práctica. Como pedagogos de oficio, educadores, sus cualidades llegaron a calificarse por parte de la clase aristocrática como algo deinós (temible), precisamente por ser expertos y hábiles en la argumentación (Protágoras, 338c; 95c).

Conforme a lo anterior, es claro que tanto en su sentido general como en el especial que se ha señalado, el término sofista no significaba un oprobio. El hecho de que Protágoras y sus seguidores se hubieran dado a sí mismos el nombre, nos hace ver que el sentido peyorativo del término es algo posterior. Es algo que obedece a toda la tradición aristocrática. En efecto, la aversión de la que fueron objeto los sofistas fue bastante general en la sociedad griega de la época, sobre todo en los grupos que mantenían el espíritu aristocrático, para los que la actividad comercial no tenía demasiado prestigio y menos el realizar un trabajo intelectual a cambio de una remuneración. Al mismo tiempo influyó el hecho de ser extranjeros.

A esos motivos vino a sumarse el juicio de Platón. Su desprecio por el ideal democrático lo llevó a criticar a aquellos movimientos que pudieran confundirse con sus doctrinas. Y en un primer momento, la necesidad de resaltar la doctrina socrática le llevó a ridiculizar a todo el grupo de sofistas, ya que, según la opinión de los ciudadanos, Sócrates ofrecía similitudes con éstos. El hecho es que, en tiempos de Sócrates, el término "sofista" fue usado, aunque no solamente, para referirse a una clase particular de educadores profesionales, que instruían a los jóvenes mediante una retribución y daban exhibición de elocuencia. La mentalidad aristocrática de Platón hace hincapié en este aspecto. Desde su punto de vista, no podría elogiarse una actividad que enseñara el arte de la oratoria y la política a la nueva clase burguesa que se estaba desarrollando y consolidando en Atenas (Protágoras, 311c). En todo caso, hay que tener en cuenta que, abarcando las actividades literarias de Platón de medio siglo, es de suponer que los sofistas contra los que se dirigen sus obras de vejez sean distintos de aquellos a los que se refieren sus obras de juventud. Cuando Platón nació (427 a. de C.), ya Aristófanes ridiculizaba a los sofistas en sus obras, lo que hace suponer que los ataques de Platón en El sofista se refieren a los círculos socráticos, como los cínicos, cirenaicos y megáricos, que eran rivales de escuela. Coincide con ello 
el que Aristóteles emplease el término para desacreditar a los socráticos de la escuela de Megara.

Entonces, los sofistas, a los que nos vamos a referir, recibieron esa calificación gracias a su habilidad para manejar la palabra entendida como un arma. Sin embargo, por los motivos aducidos, esa habilidad pronto adquirió un valor peyorativo y se identificó con los contemporáneos de Sócrates que, como Protágoras, probablemente discutieron con él (Protágoras, 349a., p. I86). También influyó en el desprecio el que no fueran ciudadanos atenienses. Gorgias, por ejemplo, fue a Atenas en el 427 a. de C., para tratar de un caso acontecido durante la expedición de Sicilia. Hipias también realizó varias misiones diplomáticas en Atenas. El hecho de que provinieran de distintas ciudades y además viajaran constantemente en misiones diplomáticas, tuvo consecuencias en sus posturas: su visión de la sociedad y de las leyes de las ciudades fue mucho más amplia de la de aquellos que rara vez salieron de su polis; ello repercutió en su concepción de los valores morales y políticos y en su crítica a la religión. En contrapartida, su carencia de un lugar fijo de residencia les impidió crear escuelas doctrinales bien definidas. No tuvieron continuadores que cuidaran sus enseñanzas y sus escritos. Esto también influyó en su desprecio ulterior.

Pero si bien no formaron escuela, ni incluso ellos mismos constituyeron una. La denominación que les abarca por igual no obedece sólo a la práctica de una docencia retribuida, sino a una serie de características:

- El cultivo de la retórica o arte de la palabra;

- La enseñanza de la areté política;

- Empirismo respecto del conocimiento;

- Escepticismo metafísico;

- Sus posturas respecto de la antítesis physis-nomos, naturaleza y convención.

- Temas comunes que autorizan a que hablemos en un sentido amplio de una mentalidad sofística o de un movimiento sofístico.

3. Los sofistas constituyeron la élite intelectual que el desarrollo de la burguesía había forjado y fueron el exponente de las características dominantes culturales de la época. La lucha entre la burguesía y la nobleza se manifestó también en el plano de la lucha intelectual, en la medida en que ésta podía ser un instrumento político de mayor importancia. El que los sofistas se presentaran como maestros de la areté política significaba, a los ojos de la aristocracia que una nueva clase asumía las funciones de la dirección política de la polis. Los sofistas 


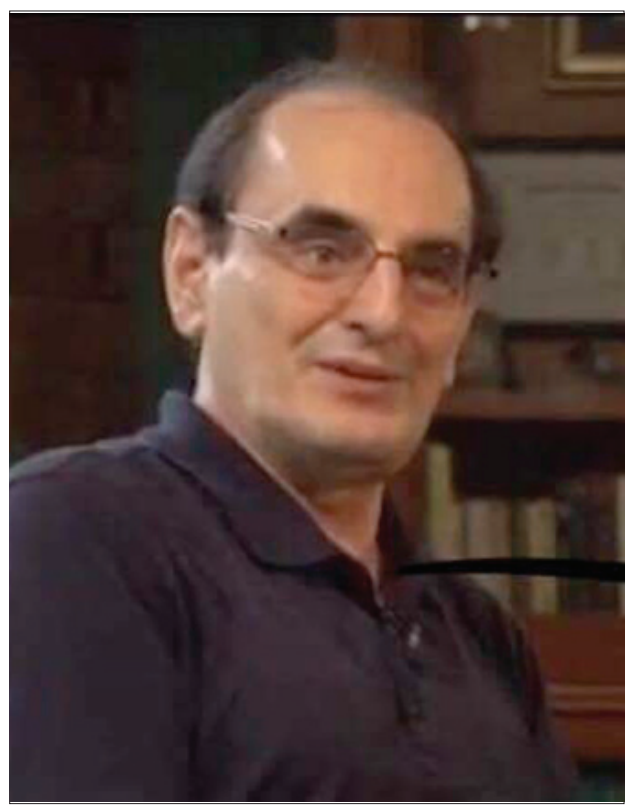

Héctor Samour

contribuyeron con sus enseñanzas a asentar la tesis de que todo ser humano es capaz de actividades políticas y, por lo tanto, a que toda una nueva concepción del mundo fuera cristalizando. Para entender mejor lo anterior, nos referimos más ampliamente al condicionamiento socio-político de los sofistas.

La vida social y política de los griegos experimentó durante el siglo $\mathrm{V}$ a. de C. grandes transformaciones. En Atenas especialmente, la lucha de clases había terminado por consolidar a la clase burguesa. Varios fueron los factores que contribuyeron a ello. Un acelerado desarrollo de las fuerzas productivas que condujeron al crecimiento del comercio griego y a la invención de la acuñación de la moneda, posibilitó que la antigua comuna campesina, que descansaba en la propiedad común y entregaba un excedente en forma de tributo, fuera reemplazada por una comunidad de propietarios individuales, que producía cada uno con independencia de los demás para el mercado abierto y donde el trabajo esclavo era el eje de producción. En otros términos, se puede decir que se produjo el cambio desde una sociedad agrícola, asentada sobre bienes inmuebles, a otra basada fundamentalmente en actividades industriales y comerciales. Conforme con este proceso, la clase mercantil emergente, poco a poco, fue conquistando el control del Estado, antes hegemonizado por la aristocracia terrateniente. Esto fue la polis griega. La revolución democrática que se produjo en Grecia en el siglo VI a. de C. significó el traspaso del poder del Estado de una aristocracia terrateniente a una nueva clase mercantil. Esta revolución se realizó en tres 
etapas: la oligarquía, o gobierno de la aristocracia latifundista, la tiranía y la democracia. Es un encadenamiento típico que no se desarrolló en todas partes por igual, con la misma regularidad. En algunos Estados no se completó jamás; en otros de los más avanzados, fue detenido o invertido. En Atenas, la tiranía de Pisístrato y la evolución de Clístenes acabaron con el dominio político de la nobleza. Este proceso se afianzó en el 160 a. de C., cuando tomaron el poder los demócratas más radicales con Efialtes a la cabeza, quien realizó una serie de reformas a la Constitución, según las cuales se aumentaba la autoridad del Consejo de los Quinientos y suponía un mayor control por parte del pueblo en la aplicación de las leyes. El partido democrático permaneció en el poder con Pericles, cuyas reformas en el año 458 a. de C., posibilitaron la participación de la nueva clase de comerciantes e industriales en las cuestiones políticas.

Este gobierno popular nacido en Atenas favoreció la discusión pública, tanto en la Asamblea como en el Consejo y, en consecuencia, hizo del dominio de la palabra algo necesario para la instrucción pública del ciudadano. A esta tarea de la enseñanza de la areté política se dedicaron especialmente los sofistas. Estos, junto con otros intelectuales, como los médicos y literatos, así como algunos filósofos, contribuyeron a formar en Atenas una concepción del hombre y del ciudadano dentro de un espíritu racional e ilustrado acorde con las necesidades de la nueva clase burguesa Es en la época de Pericles (550-528 a. de C.), cuando se produce este cambio ideológico unido a un gran desarrollo cultural. Al mismo tiempo, se producía un proceso de secularización en la misma Atenas, favorecido por el desarrollo democrático señalado; es decir, un espíritu crítico fue imponiéndose en el gobierno de la ciudad. La fe en la razón se hacía patente en los diversos campos filosóficos en consonancia con una nueva actitud.

De esta forma, se produce un desarrollo de la medicina, entendida profesionalmente como una techne (arte) que se relaciona con las demás artes y con la naturaleza humana sobre la que opera. El concepto de physis como principio universal se centra en el concepto de "naturaleza humana". Al mismo tiempo, los escritores médicos influyeron en la nueva ideología, de tal forma que el filósofo y el político son presentados por Protágoras, Demócrito y Tucídides como los médicos de la sociedad.

Aunque ya Esquilo y Sófocles apuntaban en sus obras hacia una nueva concepción de lo humano, la tragedia todavía estaba impregnada de tradicionalismo. Es con Eurípides cuando empieza una "modernización" de las figuras del mito, una transformación del lenguaje poético acorde con el espíritu de la nueva época.

En Tucídides queda también expresado el nuevo espíritu ilustrado al desarrollar una concepción de la historia que corre parejo con el abandono de la interpretación mítica de la conducta humana. Por otra parte, las críticas 
burlescas de Aristófanes son un ejemplo, en el campo de la comedia, de las discusiones que se suscitaban en Atenas sobre la igualdad de los ciudadanos, la participación de las masas en el gobierno, las crisis del sentimiento religioso, entre otros temas.

Pero hay que tomar en cuenta también la decadencia de Atenas después de Pericles. El apogeo que el movimiento democrático había tenido en Grecia después de la victoria sobre los persas, entra ahora en crisis, víctima de sus propias contradicciones. Muchas de las fuerzas sociales que habían participado y apoyado el movimiento democrático hegemonizado por la clase de los mercaderes, vieron frustradas sus esperanzas, tanto en el ámbito económico como en el político. La forma política dejó de corresponder a su contenido social. Los pequeños productores fueron arruinados al comenzar la concentración de la tierra; muchos ciudadanos perdieron sus tierras y, como carecían de la posibilidad de adquirir esclavos, se convirtieron en lumpen; además, el antagonismo entre esclavistas y esclavos se agudizó, al grado de producirse varias rebeliones. A todo esto, hay que agregar los intentos de la nobleza por recuperar el poder y que culminaron en la llamada Guerra del Peloponeso (431-404 a. de C.). La Guerra del Peloponeso también influyó en la ruptura del equilibrio social y político. Las invasiones peloponesias de Ática arruinaron totalmente a los propietarios rurales, entre los que se contaban a la nobleza y millares de campesinos poseedores de tierras. Por otra parte, la guerra produjo una grave crisis del comercio exterior y, por tanto, de las industrias; se paralizó el trabajo en las minas de plata; el número de desposeídos aumentaba sin poder ser absorbidos ni por la agricultura, ni por la industria decadente.

Los ricos se limitaban a emplear sus ganancias en cumplir con las obligaciones financieras que les imponía la ciudad, atesorando el resto. Masas populares empobrecidas y excluidas del poder político, por un lado, y aristócratas y mercaderes en situación desesperada por el otro, fue el resultado de la situación. La frustrada expedición de Sicilia en el 413, con el fin de abrir nuevos mercados empeoró las cosas. Los aristócratas aprovecharon la situación y organizaron una contrarrevolución, imponiendo un régimen oligárquico, primero en el 411 (Régimen de los Cuatrocientos) y luego, al fin de la guerra, en el 404 (Régimen de los Treinta). Finalmente, después de un período de destructiva guerra civil, las ciudades-estado griegas fueron subyugadas por los macedonios.

Todos estos acontecimientos cambiaron profundamente el marco en que se desarrollaron las enseñanzas de otros sofistas como Antifón, Hippias de Elis, Gorgias, Trasímaco, así como de gente que, como Demócrito, pertenecían a otra mentalidad filosófica. En esta época (431-404 a. de C.), el ideal de perfección y el racionalismo de la etapa anterior entra en una crisis paralela a la que sufren los ideales de la polis. Y, como dice Rodríguez Adrados, "empiezan a florecer 
filosofías que liberan al individuo y a la humanidad en general de las servidumbres de la ciudad, que ahora se consideran gravosas" (Rodríguez Adrados1975, pp. 379 ss). Ahora se habla de la igualdad fundamental de todos los hombres; de la irrealidad de las diferencias entre bárbaros y griegos, entre nobles y no nobles; e incluso se empieza a criticar la distinción entre libres y esclavos. Ahora los intelectuales se dirigen a todo el género humano y prescinden de la ciudad. Así, por ejemplo, el Eurípides de Helena y Las bacantes afirma la superioridad del nomos (ley) de los bárbaros frente a la de los griegos. Parte del hecho de que son convencionales las diferencias que establece el nomos y verdadera únicamente la unidad de naturaleza. En otra parte, proclama que la patria del pobre está allí donde encuentra de comer. En su Alejandro se discute la cuestión de si la esclavitud es "por naturaleza" o por "nomos". También aparece en Eurípides una nueva concepción del matrimonio en que la mujer no es "esclava" del marido, sino que siente con él. No se pude condenar a las mujeres en bloque, sino que, como entre los hombres, hay entre ellas naturalezas diferentes. La situación social de la mujer es criticada abiertamente por la heroína en Medea.

Pero, aparte de las tesis de la igualdad humana, también se va produciendo otra ideología para la cual es lógico que mande el hombre dotado de una naturaleza superior. Gorgias y sus discípulos son los representantes de esta corriente de pensamiento. Arrancan de la concepción de la naturaleza humana según la cual ésta contiene elementos irracionales que se imponen al logos y que condicionan las relaciones humanas. Lo irracional no es condenado, sino aprobado como "natural". Lo contrario es nomos convencional, que hay que destruir, lo mismo cuando se opone al placer, que cuando obstaculiza el dominio del más fuerte. La esfera política debe ser un campo abierto a la acción del individuo, que busca satisfacer su naturaleza. El éxito no va ligado necesariamente al bien de la comunidad ni a valores universales. Platón hizo derivar en el Gorgias las doctrinas de Polo y Calicles del propio Gorgias, a quien considera como fuente implícita de sus errores. Esta "naturaleza superior" puede ser la de cualquier ciudadano, y en las versiones más moderadas no tiene que chocar necesariamente con los intereses de la polis. Calicles presenta como ejemplos de naturaleza superior a estadistas atenienses como Temístocles, Pericles y otros (Gorgias, 415c). También Trasímaco argumenta en el libro I de La República platónica, que la justicia es la "convención del más fuerte".

Frente a la tendencia inmoral implícita en la ideología anterior, surge una tendencia moralista, cuyo máximo representante es Sócrates. Éste representa una reacción frente a la disolución de los valores en el pensamiento de la segunda sofística y en la misma sociedad contemporánea desgarrada por la guerra. A causa de la ruptura de la solidaridad entre los valores individuales y colectivos, ahora son los del individuo los que prevalecen, sean entendidos como el derecho del más fuerte, o como un hedonismo humanitario y político. 
Frente a estas posiciones, Sócrates vuelve a hacer un llamado a la virtud o areté, y pretende asentar esta areté sobre bases firmes y universalmente válidas, alejadas de todo relativismo.

4. La característica más importante del cambio intelectual y cultural del que hemos hablado es la antítesis entre physis y nomos, que está subyacente en la mayoría de los temas tratados por los sofistas. Así, por ejemplo, en la cuestión religiosa, la discusión depende de la consideración de que la creencia en los dioses responde a la physis, o sea, un producto del nomos; en política, sobre si los Estados surgen por orden divina, por necesidad natural o por convención, etc. Los términos nomos y physis aparecen en el pensamiento griego de los siglos V y IV a. de C. como antitéticos, cosa que no sucedía en tiempos anteriores. La physis es lo que está a la base de la realidad absoluta de las cosas, mientras que el nomos es lo que se cree convencionalmente y se practica por considerarlo correcto. Es algo decidido y puesto por el hombre. Si tradicionalmente el derecho estaba fundamentado por el designio de los dioses, al surgir en el siglo IV a. de C. la idea de naturaleza como algo ordenado, como un "cosmos", se produjo un cambio en esa fundamentación; la physis adquirió realidad autónoma frente a la voluntad de los dioses y, al mismo tiempo, se convirtió en el fundamento de las leyes humanas. Pero cuando las leyes comienzan a ser vistas como producto tan sólo del nomos, entonces quedan separadas, no sólo del orden divino, sino también del orden natural. Va creciendo así una oposición entre quienes creen que las leyes provienen de una necesidad absoluta, que identifican con la physis, y los que creen que son los hombres los que convencionalmente han establecido sus propias leyes y que éstas, por tanto, se basan en la sociedad misma.

En tiempos de los sofistas, la oposición nomos-physis se circunscribe al orden de la moral y la política. Las posturas de los sofistas se van fijando en torno de las discusiones sobre el origen de las leyes, del Estado, de la sociedad y sobre el fundamento de la justicia. En esta controversia se dan varias posturas; los defensores del nomos contra la physis, como es el caso de Protágoras; la actitud intermedia, o de "realismo político", defendida por Tucídides y Trasímaco; y la de Antifón, en la que prevalece la defensa de la physis como fundamento de las leyes. Todas estas posturas hay que situarlas en el contexto que antes apuntábamos, en el desarrollo de un Estado democrático en el que los intentos de la oligarquía por recuperar el poder eran una constante amenaza; era, pues, una controversia teórica y práctica a la vez.

Protágoras defendió la teoría del progreso del hombre de la sociedad, y es en la exposición de la misma donde podemos encontrar sus ideas sobre el fundamento de las leyes. La cuestión se plantea a partir del diálogo entre Sócrates y Protágoras acerca de la posibilidad de enseñar areté (Prot., 320c). La posición de Protágoras es difícil en la medida en que, si se sostiene que la areté es algo 
inherente a la naturaleza humana y no puede adquirirse por aprendizaje, va en contra de su propia profesión, que es enseñar areté. Pero, por otra parte, tiene que justificar el principio inherente a la democracia ateniense, según el cual, la política no es una cuestión de "unos pocos", sino que la opinión de cualquiera es tan buena como la de los demás, lo que implica que las virtudes políticas ya están por naturaleza en cada hombre.

En el mito de Prometeo y Epimeteo (Prot., 320d-e; 321, 322), Protágoras relata que por encargo de Zeus, los dos hermanos distribuyeron distintas capacidades entre los seres vivos, de tal manera que hubiera un equilibrio entre ellos para que todas las especies llegaran a vivir. Al llegar al hombre, viendo que se le habían acabado los bienes, Prometeo le dio el fuego, símbolo de la sabiduría técnica, que distinguiría al hombre de los demás animales, y con su ejercicio le permitiría su supervivencia. "De esta manera, el hombre recibió en posesión las artes útiles a la vida, pero se le escapó la política". En la explicación que sigue del mito, Protágoras considera que las virtudes políticas son necesarias para el desarrollo de una polis y que pueden y tienen que ser poseídas por todos los hombres. Si bien las otras virtudes pueden faltar, el "amor" y la "justicia" tienen que estar en todos los hombres, pues de otra manera las ciudades no podrían subsistir.

Ahora bien, si es cierto que la naturaleza humana conferida por los dioses hace posible el progreso moral, gracias al don del amor y la justicia, su realización requiere del aporte, tanto de la experiencia individual y colectiva y de la educación que orienta y estimula. En otras palabras, la vigencia de las leyes que posibilitan y mantienen la comunidad política, no es simple resultado de la imposición de los dioses, ni tampoco de una necesidad de la naturaleza, sino que depende también de los acuerdos tomados por los hombres, de algo que posteriormente se llamará "contrato social". Las leyes se basan en ciertas tendencias éticas implantadas en todos los hombres, pero las concreciones y variedades de éstas, tal como se encuentran en los diversos Estados, son relativas, y la ley de un Estado no es más verdadera que la de otro, pero sí más útil, más ventajosa. El mismo nomos es, por tanto, fundamento de la práctica de la justicia y de las virtudes políticas. Con ello se pone de manifiesto la importancia de la convención con respecto a la naturaleza, al mismo tiempo que se eleva al primer plano el tema de la educación.

Veamos cómo sigue discurriendo el Protágoras platónico: nadie se avergüenza de confesar su incapacidad en un arte que exige capacidad especial. Por el contrario, nadie comete públicamente delito contra la ley si trata de guardar las apariencias de actuar legalmente. Si abandonara las apariencias, nadie creería que se trata de sinceridad, sino de locura (Prot., 323a ss.). La posibilidad de adquirir la areté se sigue del sistema dominante de premios y castigos públicos. 
Los premios y los castigos son dados por la sociedad, en cuanto el aprendizaje se trata de un bien que puede ser alcanzado por el esfuerzo consciente. Ahora bien, las faltas de los hombres que castiga la ley deben también ser evitables mediante la educación, a menos que el sistema entero sobre el cual descansa la sociedad sea insostenible.

Lo mismo concluye Protágoras del sentido de la pena o castigo. Contra la antigua concepción causal, que imagina la pena como retribución de la falta cometida, se acepta una teoría enteramente moderna para la cual la pena es un medio para llegar al mejoramiento del transgresor. Hay, pues, una concepción pedagógica de la pena y que descansa en el supuesto de la posibilidad de educar al hombre, precisamente porque éste tiente una tendencia innata al bien y a la justicia. La virtud ciudadana es el fundamento del Estado. Ninguna sociedad podría subsistir sin ella. Quien no participe de ella debe ser educado, castigado y corregido, hasta que se haga mejor. Dentro de una concepción que, como la de Protágoras, mantenga que puede ser enseñada la areté política y que todos los hombres tienen acceso a ella mediante la educación, lo que se está poniendo en juego es una paideia nueva, contrapuesta a la aristocrática, en la cual la areté sólo era posible para los que poseían una physis o naturaleza especial debida a su sangre. Al mismo tiempo, introduce una nueva concepción basada en la convicción de que todos los hombres poseen naturaleza común. Pero ya no se trata de una naturaleza que decida la totalidad de leyes humanas, sino que sólo presta el fundamento general para que la convicción, ayudada por la educación, establezca las leyes en cada caso.

Una postura "realista" fue la mantenida por Tucídides y por Trasímaco, oponente de Sócrates en La República. La tesis de Tucídides será la de mantener una ley natural entendida como el derecho del más fuerte que, ni se subordina al nomos tradicional, ni lo suprime. Un principio básico de Tucídides será el no usar argumentos morales en las discusiones sobre lo que sea la justicia, ya que considera que ésta depende del poder: el más fuerte es el que manda y decide, y el más débil es el que se somete. Las consideraciones deben centrarse en el poder político más que en una dilucidación de lo que sea la justicia. En La Guerra del Peloponeso se establece que para los atenienses hay una necesidad natural que determina quién es superior, y aunque no se establezca como ley, esta necesidad es practicada. El principio según el cual el débil ha de someterse al más fuerte es una cuestión política y en ella será el interés del más fuerte el que prevalezca, y no la justicia: "Nuestra opinión sobre los dioses y el conocimiento de los hombres, nos lleva a concluir que es una ley general y necesaria de la naturaleza dominar siempre que sea posible. No es esta una ley que nosotros hayamos inventado, ni somos los primeros en actuar conforme a sus dictados. La encontramos ya y la dejamos, porque ha de seguir subsistiendo para siempre entre aquellos que nos sobrevivan. Nosotros actuamos de acuerdo con ella, y 
sabemos que vosotros o cualquier otro con igual poder que el vuestro procederá de la misma manera" (Citado por A. Llanos, 1969, p. 151).

La postura de Trasímaco en La República resulta ser parecida a la de Tucídides. En la discusión que presenta Sócrates para averiguar el significado del término "justicia", Trasímaco expone su propia definición: "Sostengo yo que la justicia no es otra cosa que lo que conviene al más fuerte. En todas las ciudades, la justicia no es sino la conveniencia del gobierno establecido. Y éste, de una $\mathrm{u}$ otra manera, es el que tiene el poder. De modo que, para todo hombre que razone sensatamente, lo justo es lo mismo en todas partes: lo que conviene al más fuerte" (338b-e). Lo que trata de decir Trasímaco es que "la justicia es en realidad un bien ajeno, conveniente para el más fuerte y el que gobierna, y un daño para el que obedece y está sometido; y que la injusticia es su contrario y ejerce su dominio sobre los verdaderamente sencillos y justos, que, mandados, hacen lo conveniente para el más fuerte y, sirviéndole, aseguran su felicidad y no la propia... que al hombre justo le va peor en todo lugar y circunstancia que al hombre injusto" (342c-e). Hay que observar que la discusión con Sócrates se mantiene en dos niveles distintos. Éste trata de buscar una definición esencial de la justicia. Trasímaco, por el contrario, está dando una información sociológica sobre el asunto. Este es el sentido que tiene su afirmación de que la injusticia es más provechosa que la justicia. Está constatando un hecho, está afirmando una situación que se da: por ello observa que en realidad la justicia perjudica a los que se creen justos al margen de su poderío o de su fuerza. Es decir, los que creen en una justicia ideal se convierten en víctimas propicias para los más fuertes y, en definitiva, favorecen lo que, en su opinión, es una injusticia. Por ello, Trasímaco propone un nuevo concepto de justicia, equiparado a la fuerza o poderío.

Tanto la postura de Trasímaco como la de Tucídides representan la defensa de la tesis que asocia la physis a la "necesidad". El gobierno del más fuerte ocurre por necesidad natural. Las leyes de la naturaleza son inexorables y determinan a los hombres tanto como al mundo en general. Sería insensato, por consiguiente, que el hombre intentase establecer un dominio de leyes distintas a las que impone su propia naturaleza. También el Gorgias platónico presenta a Polo y Calicles sustentando esta misma postura (Gorgias, 482 ss).

La exposición del nomos como fundamento de la justicia y la defensa de la physis tienen en Antifón una relación peculiar. Antifón afirma que la justicia consiste en lo que es legal dentro de una ciudad determinada. Mientras que los imperativos de la physis son necesarios, considera que los de la ley son convenientes. La justicia es una cuestión social, y si no fuera por las presiones sociales, el interés del hombre estaría en seguir su naturaleza, pues los imperativos de la ley no obligan con necesidad, mientras que los de la naturaleza sí, y las convenciones 
sociales admitidas por los hombres por contrato mutuo no son naturales. En su estudio Sobre la verdad, expresa la necesidad de la naturaleza frente a la convencionalidad de las leyes, con lo que pone de manifiesto la distinción entre regularidades necesarias - leyes naturales - y unas prescripciones - leyes normativas - que, precisamente por ser dictadas por alguien, no tienen por qué obligar con necesidad. El origen de las leyes convencionales del nomos está en el contrato mutuo de los hombres. Ahora bien, aunque las leyes convencionales carezcan de la necesidad que es propia de la naturaleza, poseen, sin embargo, una fuerza constructiva derivada de las presiones sociales que las han dictado. Por ello, Antifón plantea que "las cosas que la ley decreta como útiles son cadenas que aprisionan la naturaleza, mientras que las cosas útiles declaradas como tales por la naturaleza son libertades" (citado por Campillo I. y Vegas G., 1976, p. 83).

Esta defensa de la physis por Antifón está basada en la defensa de la libertad individual frente a la coerción social. Por esto, discutirá la postura de Protágoras, en la medida en que éste justifica las leyes, ya que son, justamente, las que han posibilitado la comunidad. Al mismo tiempo, Antifón pone de manifiesto el carácter contradictorio de la justicia, en tanto que se basa en la convención, en la opinión, y no en la naturaleza o en la verdad. Por ello, en un juicio no se puede ser justo sin ser injusto al mismo tiempo. Está claro que, de seguir la naturaleza, se conseguiría llegar a la verdad, pero como la justicia se determina a partir de leyes particulares que rigen en cada ciudad, su práctica conduce a contradicciones.

La crítica al nomos de Antifón no tiene las mismas consecuencias que la contenida en la ideología de Tucídides, Trasímaco y Calicles. Mientras éstos hacen hincapié en la desigualdad de la naturaleza frente a la igualdad que proporciona el nomos, la postura de Antifón implica que la igualdad no se da en la sociedad. Su crítica de la convención social apunta hacia ideas más universalistas, que propugnan por una igualdad natural entre los hombres. Pues, por naturaleza, no hay distinción entre nobles y pobres, entre griegos y bárbaros. Los hombres, sin excepción, deben observar las mismas leyes de la naturaleza, desarrollando sus aptitudes. Si la crítica al nomos en Calicles, por ejemplo, podía ser la justificación de una contrarrevolución oligárquica, la crítica de Antifón supone una revuelta individualista por la que se reconoce la legitimidad de la libertad individual que tiene cada uno para obrar conforme a su naturaleza. En otros términos, la conducta acorde con la naturaleza viene a coincidir con los deseos del individuo, libre de la coerción que imponen las reglas sociales. Esta es una idea que también expresa Hippias. "Todos los presentes sois a mis ojos semejantes, parientes y ciudadanos, no por la ley, sino por la naturaleza. Por la naturaleza, lo semejante es pariente de lo semejante, pero la ley tiraniza a los hombres, constriñe muchas cosas de la naturaleza" (Prot., 337c). 
Todas las investigaciones que sobre la naturaleza de las leyes hicieron los sofistas partían del supuesto de que son las leyes las formas de conducta que mantienen a los hombres en sociedad. Es decir, las relaciones sociales y la estructura social eran estudiadas por los sofistas a través de las leyes. Con esto, se planteaban problemas de filosofía del derecho y también elementos sociológicos. Todo lo cual llevó a que los sofistas trazaran una concepción distinta de la que habían desarrollado los pensadores "presocráticos", cuyo campo de investigación sólo había sido la physis.

5. Con respecto a la religión, tampoco hay en los sofistas una postura unitaria. Sí se puede decir que, en general, sostuvieron una actitud crítica de corte racionalista, independientemente de sus creencias religiosas personales, y que concibieron el fenómeno religioso como un hecho social determinado por motivos económicos, sociales y políticos, dejando al margen lo sobrenatural. En general, su postura es agnóstica, eludiendo cualquier compromiso respecto a la existencia de los dioses. Es obvio que esta postura escandalizó a la gente religiosa de su tiempo, las cuales no dudaron de calificarla de ateísmo. Sin embargo, los sofistas nunca pretendieron involucrarse en discusiones sobre la naturaleza y existencia de los dioses. Sólo atendieron a la religión como un hecho natural y su crítica se centraba en la función política que desempeñaba.

El caso más conocido es el de Protágoras que, acusado de ateísmo, tuvo que abandonar Atenas, siendo sus libros quemados públicamente. Su tesis más famosa, único fragmento que quedó de su libro Sobre los dioses, dice así: "Con respecto a los dioses, no tengo medios para saber si existen o no; pues muchos son los obstáculos que me impiden su conocimiento: entre ellos, la oscuridad de la cuestión y la brevedad de la vida del hombre" (citado por A. Llanos, 1969, p. 39). Es claro que el fragmento es más bien una declaración de agnosticismo que de ateísmo. La postura de Protágoras tiene que ver con el conocimiento que podemos tener de los dioses y está basada en la argumentación de que nuestro conocimiento no puede ir más allá de lo sensible, por lo que nada se puede decir sobre la existencia de seres divinos que se sitúan más allá del alcance de los sentidos. Sin embargo, aunque la sentencia sólo muestra una postura escéptica respecto al conocimiento de los dioses, como muestra Llanos, no es posible negar que su crítica a la religión fuera mucho más amplia, sobre todo si se tiene en cuenta que una de las características de los movimientos ilustrados de todos los tiempos es la crítica a la superstición religiosa. Y Protágoras no parece ser la excepción, como integrante de una ideología de avanzada que se está abriendo paso en el mundo cultural de Atenas de aquel entonces (Ibídem).

En otra dirección, Pródico señala el origen natural de los cultos y se le atribuye la teoría de que todas las cosas útiles al hombre son tomadas como dioses. En un texto de Sexto Empírico se dice: "los antiguos consideraban dioses, en 
vista de las ventajas que de ello se obtenía, al Sol, la Luna, los ríos, las fuentes, $\mathrm{y}$ en general a todas las fuerzas que favorecen nuestra vida, como hacían los egipcios con el Nilo; por tal causa, el pan era Démeter; el vino, Dionisio; el agua, Poseidón; el fuego, Hefaisto, y así cada uno de los fenómenos que resultaba útil..." (citado por Campillo y Vega, 1976, p. 87). Pródico, lo mismo que Protágoras, pensaba en la religión como uno de los frutos de la civilización. Su postura ha de ser considerada dentro del contexto del progreso de las fuerzas productivas y desarrollo de las relaciones sociales que ya hemos señalado. Desde su punto de vista, está de más sostener la existencia de unos dioses que fuesen independientes de la creencia que los hombres tuvieran de ellos. Era inevitable que se tendiera a concebirlos como fruto de esa misma civilización que creaba convenciones de todo tipo.

El origen social de la religión lo mostró Critias. En su obra Sisifo presentó la creencia religiosa como una imposición deliberada de los gobernantes para legitimar su poder y su dominación ante sus súbditos. La base de su discurso es la idea de progreso de la vida humana desde el estado del salvajismo. Dice Critias: "...hubo una época en que la vida de los hombres era desordenada, sometida a impulsos brutales; en ella no había recompensa para la virtud, ni castigo para el malvado. Entonces, los hombres inventaron las leyes para que prevaleciera la justicia. Pero con ello no se impedía que los crímenes se cometieran en secreto. Por ello, alguien, muy sabio, descubrió el temor de los dioses para contener la perversidad, amedrentando a los malvados. Afirmó que hay dioses que viven eternamente, que lo conocen todo, incluso las calladas intenciones de los mortales. Dijo que moraban en lugares que despertaban el mayor respeto entre los humanos: en la bóveda celeste de donde surge el rayo, el trueno y la benéfica lluvia, en la que luce radiante el sol. Con ello, combatió la indisciplina de los hombres" (citado por Campillo y Vegas, 1976, p. 88).

Esta teoría recoge las tesis de Pródico y Demócrito según la cual la creencia en los dioses era un producto del miedo o de la gratitud producida por los fenómenos naturales. Pero Critias añade la consideración de la eficacia política del deseo de un castigo sobrenatural para la conducta humana. En general, los análisis sociológicos de la religión estaban vinculados a la cuestión del origen de las leyes. Pero lo que interesaba a los sofistas no era sólo una mera teoría sociológica del fenómeno religioso, sino su incidencia en la realidad política.

6. La tesis de Protágoras que plantea que "el hombre es la medida de todas las cosas: de las que son como son y de las que no son como no son" tiene una vertiente epistemológica de gran importancia. Con ello confirma su alcance como expresión adecuada de lo que significó el movimiento sofista, que centró en lo humano la nueva filosofía que emergía con él. 
La interpretación clásica de la sentencia con que Protágoras comienza su libro La verdad, es debida a Platón. En el Teetetos, Platón identifica la postura de Protágoras con la de aquellos que defienden el conocimiento sensible, concluyendo así que para él la ciencia podría ser reducida a pura sensación. No se va a negar que Protágoras fuera un partidario de la percepción como forma fundamental del conocimiento. En este sentido, hay una vinculación con Demócrito, en cuanto que ambos expresarían una crítica a Parménides, y al eleatismo en general por mantener que el objeto del conocimiento racional es algo inmutable. Pero ni una ni otra cosa hace suponer que Parménides defendiera un subjetivismo sensualista. Es difícil sostener esto, sobre todo en Protágoras, que había manifestado su confianza en la razón. Las discusiones sobre el fundamento de las leyes y de la sociedad, su confianza en la educación política del hombre, su crítica a la religión, señalan que era partidario de concepciones racionalistas del hombre. En otras palabras, la valorización del conocimiento sensible hecha por Protágoras no se puede desligar de su fe en la razón, ni tampoco de su concepción del individuo como ciudadano.

En realidad, lo que supone el racionalismo de Protágoras es una crítica de la investigación propuesta por Parménides para alcanzar la verdad, y es precisamente el eleatismo lo que está a la base de la teoría platónica del conocimiento, según la cual el objeto del conocer es algo universal e inmutable. Lo que rechaza Protágoras es que el conocimiento sensible sea considerado como algo secundario en favor de un saber que tenga por base una intelección ideal. Reivindica plenamente la posibilidad del conocimiento de lo cambiante, manteniéndose escéptico respecto de la posibilidad de una ciencia que prescinda de lo sensible. Su escepticismo lo es sólo respecto de la especulación metafísica, ya que, por otra parte, tiene plena confianza en la posibilidad de la razón del hombre para hacer ciencia.

El mismo Sexto Empírico, que trata de hacer de Protágoras un defensor de las tesis escépticas, al establecer sus diferencias con los pirrónicos, especifica el sentido de su relativismo y el de su pretendido individualismo, diciendo: "Sin embargo, difiere de ellos, y advertiremos la diferencia cuando hayamos explicado adecuadamente las opiniones de Protágoras. Lo que él afirma es el fluir de la materia y que a medida que fluye se agregan de forma continua otras partículas en el lugar de las que desaparecen; y las percepciones se transforman y modifican de acuerdo con las etapas de la vida humana y las condiciones de cada organismo. Dice también que las explicaciones de todos los fenómenos residen en la materia (yle), de modo que ésta, en cuanto depende de sí misma, es capaz de ser todas aquellas coas que aparecen a todos. Los hombres captan objetos distintos en momentos diferentes, debido a sus peculiares aptitudes, pues quien se halla en estado normal aprehende las cosas que subsisten en la materia y que pueden presentarse a los que se hallan en estado normal, en tanto 
que los que padecen deficiencias orgánicas sólo las perciben según el estado en que se encuentran. Además, precisamente la misma explicación se aplica a los cambios de edad, a los estados de sueño y vigilia, y a cada uno de los distintos tipos de condiciones. Así, de acuerdo con Protágoras, el hombre se convierte en el criterio de la existencia real; pues todas las coas que se presentan a los hombres existen, y las cosas que a nadie se presentan no existen" (citado por A. Llanos, 1969, p. 32).

Además, hay que tener en cuenta que los intereses científicos de Protágoras no tenían por objeto la naturaleza, sino el hombre y la sociedad. Esto es fundamental para entender la sentencia protagórica. Se trata de un cambio radical temático, determinado por la crisis que experimenta la teoría de la naturaleza definida por una entidad inmutable o ajena a los cambios que registra la realidad sensible. El concepto mismo de naturaleza, bajo la influencia de Heráclito, pasa a ser algo cambiante como lo son los hechos históricos y sociales que la praxis del hombre transforma. La imagen de la naturaleza se descarga de la inmutabilidad que el eleatismo le había conferido. No hay un ser fijo e inmutable dado de una vez y para siempre. Hay un mundo que deviene, y en el campo de la praxis social, la única realidad existente que actúa siguiendo fines es el hombre, que tiene necesidad de ubicarse ene ella con toda su inteligencia y capacidad interpretativa, no sólo para comprender el proceso, sino para dominarlo y utilizarlo en favor de la comunidad. Por ello, el criterio para definir la verdad no depende de lo inmutable, sino del hombre como ente social, como ciudadano, que modifica su entorno social y la naturaleza misma. Si es el hombre el que actúa, el criterio de verdad será su capacidad cognoscitiva, que dará cuenta de las cosas, de los hechos históricos y sociales, de los valores, por ejemplo. Pero ese conocimiento será analizado, a su vez, no como el conocimiento aislado que posee un individuo, sino el conjunto de ellos formando polis. Difícilmente, esto puede ser considerado como subjetivismo o individualismo.

Gorgias, por otra parte, lleva la crítica al eleatismo hasta sus últimas consecuencias. Su trabajo más importante, en el que expresa dicha crítica y su concepción del conocimiento, es el tratado Sobre el no-ente o Sobre la Naturaleza. Gorgias pretende probar: a) que el Ser no es; b) que si fuera, sería incognoscible para el hombre, y c) si fuera cognoscible para alguien, no podría ser comunicado. Tanto para el sentido común, como para la retórica de la época, era necesario presentar lo absurdo de la lógica eleática. La obra de Gorgias tiene el sentido de ser una parodia y crítica del parmenidismo. Al decir que "lo ente no es", Gorgias rechazaba el supuesto subyacente a los sistemas presocráticos que habían mantenido la existencia de una realidad más allá del mundo de las apariencias. La tesis de Gorgias pretende destruir todo tipo de apariencias permanentes. 
Los argumentos que utilizó para apoyar su tesis son los siguientes: para la primera, "lo ente no es", da dos argumentos. Si algo es, debe ser el Ser no el No-Ser, o a la vez el Ser y el No-Ser. No puede ser el No-Ser, pues el No-Ser no es; si fuera, sería al mismo tiempo el Ser y el No-Ser, lo que resulta imposible. Sexto Empírico explica así la argumentación de Gorgias: "No puede ser el Ser, porque el Ser no existe. Si existiera, debería ser eterno o creado, o ambas cosas a la vez. No puede ser eterno, pues si lo fuera carecería de comienzo y, en consecuencia, sería infinito. Mas, si fuera infinito, carecería de lugar, porque si lo tuviera estaría contenido en algo, en este caso ya no sería infinito; pues el continente es mayor que el contenido, y nada es mayor que lo infinito. No puede tampoco estar contenido en sí mismo, porque entonces lo continente y lo contenido serían idénticos y el Ser devendría dos cosas, lo que es absurdo. De aquí si el Ser es eterno es infinito; si es infinito, carece de lugar; si no tiene lugar, no existe. De igual modo, el Ser es increado; de lo contrario, provendría de algo, ora del Ser, ora del No-Ser, lo que es imposible. Similarmente, el Ser no puede ser a la vez eterno y creado, porque son contrarios. Luego, el Ser no existe. El Ser no puede ser lo Uno, porque si éste existiera, tuviera magnitud y a la vez divisibilidad infinita; sería, por lo menos, triple, al poseer longitud, anchura y profundidad. No puede ser múltiple, ya que lo múltiple se compone de adiciones de unos, y puesto que lo Uno no existe, tampoco lo múltiple existe. La mezcla del Ser y del No-Ser también es imposible. Por lo tanto, si el Ser no existe, nada existe" (citado por A. Llanos, 1969, p. 53).

El segundo argumento expresa que si algo es, sería incognoscible para el hombre. Sexto Empírico parafrasea a Gorgias de este modo: si los conceptos de la mente no son realidades, la realidad no puede ser pensada. Si la cosa pensada es blanca, entonces se piensa lo blanco. Esto equivale a decir que la existencia, la realidad, no puede pensarse. Muchas de las cosas en que se piensa carecen de realidad: podemos concebir un carro que corre por el mar, o un hombre alado. Ahora bien, si aceptáramos la realidad de las cosas pensadas sin haberlas visto ni oído, tendríamos que creer en cosas tales como el carro que corre sobre el mar. En ese supuesto no podrá haber errores.

Por consiguiente, lo que quiere decir Gorgias es que si nuestro pensamiento no puede identificarse con el Ser, tampoco se puede asegurar que, de existir éste, fuera necesariamente objeto de pensamiento. La mente pura, como opuesta a la percepción sensible o aun como criterio de verdad igualmente válido, es un mito.

Para probar la tercera tesis - que plantea que si el ser fuera cognoscible, no podría ser comunicado - Sexto Empírico dice que Gorgias argumentaba así: las cosas que son, son perceptibles; pero los objetos visibles son aprehendidos por la vista; los audibles, por el oído, sin que estas percepciones sean intercambiables 
entre sí. Ahora bien, si el medio con que nos comunicamos es el discurso y éste no coincide con las cosas que son, no transmitimos estas mismas, sino tan sólo la palabra. De igual modo que lo visto no puede convertirse en oído, tampoco nuestro discurso se armoniza con lo existente, que se halla fuera de nosotros. Por otra parte, el discurso depende de efluvios que recibimos del exterior, esto es, de percepciones. Pero el discurso no comunica las percepciones, sino lo que éstas crean en él. Por eso, la palabra no puede nunca representar exactamente las percepciones, porque difiere de éstas, las que son aprehendidas por el órgano correspondiente, mientras que el discurso tiene su propio medio expresivo. En consecuencia, como los objetos visibles sólo pueden presentarse a los órganos de la visión y los diferentes órganos sensibles no dan su información a otros, de manera similar el discurso tampoco logra aportar conocimiento sobre las percepciones.

Aunque los argumentos de Gorgias van dirigidos expresamente contra el Ser parmenídeo, no cabe excluir que en definitiva atacasen a todos los autores presocráticos que habían concebido la physis bajo el esquema parmenídeo, es decir, como sustentada por principios trascendentes al carácter empírico de las cosas, constituyendo un dominio de entidades eternas o inmutables, ajena a la diversidad cambiante de lo que percibimos.

7. Dentro de la discusión que determinó la distinción entre el nomos y la physis, cabe distinguir dos posturas: por una parte, era posible sostener que la ley y la costumbre - y con ello, la totalidad de las impresiones sensibles - fueran definidas como cambiantes y relativas frente a la naturaleza inmutable y eterna, de lo que se infería la imposibilidad del conocimiento científico, dado que no era posible acceso alguno a esa realidad permanente. $O$, por otra parte, reivindicar la posibilidad de un conocimiento de lo sensible, asumiendo las dificultades que ese conocimiento y su transmisión en el lenguaje presentan. Esta fue la postura de Protágoras y Gorgias. Aunque hay diferencias entre ambas, tienen mucho en común, como lo muestra la teoría del "doble argumento". En efecto, según el testimonio de Sexto Empírico, "los griegos afirman, y el primero de ellos, Protágoras, que a toda tesis puede oponerse otra" (citado por Campillo y Vegas, 1976, p. 100).

Esta teoría fundamentaba la posibilidad de utilizar la retórica como procedimiento para hacer prevalecer cualquier punto de vista. Pero, además, la técnica de la persuasión sustentada por el "doble argumento" se fundamentaba en la convicción de que toda verdad es relativa y que la posibilidad real del conocimiento está en los límites de la doxa. Gorgias, por ejemplo, utilizó las técnicas de la retórica para resolver problemas de la lingüística y la lógica que iban más allá de un puro malabarismo discursivo. Es decir, implicaban la admisión de que es posible justificar conocimientos relativos a unos determinados 
supuestos y a unas experiencias concretas, sabiendo que, cambiando éstas, se podía llegar a la conclusión opuesta. Todo ello se fundamentaba en la renuncia a un conocimiento de una realidad absoluta, como el Ser eléata.

La postura de Antifón es distinta a la de Gorgias, y más parecida a la de Demócrito, al mantener la realidad de los datos empíricos. Antifón critica la ambigüedad del lenguaje al expresar la realidad. Cuando un hombre dice algo, no hay un significado único al que corresponda algo en la realidad, "ni entre los objetos que la vista más penetrante percibe, ni entre los objetos que la mente en el conocimiento más penetrante conoce" (citado por Campillo y Vegas, 1976, p. 101). Pero los sentidos sí pueden constituir una vía de conocimiento de la realidad más allá del perceptible flujo de lo físico. El contraste entre lo natural (la percepción) y lo artificial (el lenguaje) es resuelto por Antifón considerando la primacía del primero frente al conocimiento por convención. Así, analizando el lenguaje, considerará que los nombres que tienen un significado único los comunes - no están basados en la naturaleza, ya que no hay nada que les corresponda exactamente en lo empírico. Son rechazados, por tanto, en beneficio de aquellos que no tienen un significado único (universal) y que pueden referirse a cada una de las cosas que percibimos por los sentidos.

El problema del significado de las palabras y de los nombres era uno de los temas más debatidos dentro de la problemática más amplia sobre cómo pueden ser conocidas las cosas. El problema que planteó Sócrates con referencia a los términos morales entraba de lleno en el debate. Según Platón, el tema fue tratado por Protágoras, Pródico y los sofistas en general (Cratilo, 391c). Por lo tanto, el uso del lenguaje, su precisión, la definición de los términos y su relación con los objetos no fueron ajenos a la sofística. El tema constituía una preocupación general entre los intelectuales de la época, tanto por su interés teórico como por la repercusión que estos problemas tenían en las discusiones prácticas de la vida social. El uso incorrecto de los términos que Sócrates denuncia debe verse en el contexto de un gran interés por buscar las posibilidades y limitaciones del lenguaje e insertarlo en el marco más general de los debates ético-políticos y religiosos, en un momento de crisis que asistía a un cambio en las normas y valores que hasta entonces habían proporcionado cohesión a la sociedad. Los sofistas eran una alternativa; Sócrates, otra. El estudio de la Gramática tiene el mismo sentido: procurar reformas del lenguaje que aumentasen su eficacia. Protágoras fue el primero en dividir el discurso en cuatro clases: súplicas, preguntas, respuestas e imperativos. Además, distinguió los géneros masculino, femenino y neutro, y se ocupó de la estructura de los tiempos y modos verbales (Aristóteles, Poética, 1456b; Retórica, 1407b).

Pródico es considerado como uno de los que más insistieron en la corrección del lenguaje, especialmente en el estudio que hizo de los sinónimos. Para Pródico, 
las dificultades en la transmisión del conocimiento por medio del lenguaje podrían ser salvadas por el ejercicio de precisar cada vez más los términos del lenguaje y su significación. Con ello, criticaba la postura de Gorgias y mantuvo que la palabra es un buen medio para la enseñanza (Platón, Eutidemo, 277e; Cratilo, 384b; Protágoras, 337a-c).

Como balance final, se puede concluir que la filosofía de los sofistas constituye uno de los momentos claves de la historia de la filosofía griega. Lejos de ser un grupo de pensadores superficiales con un absurdo afán de destruir todo fundamento de una auténtica filosofía, los sofistas aparecen como los iniciadores de un giro decisivo en la historia del pensamiento humano, que puso en primer plano los problemas de la vida social y ética, junto con la dilucidación de lo que fuesen las leyes y de las normas morales, así como de la inserción del hombre en su medio histórico y natural. Frente a la rigidez dogmática que afectaría a las doctrinas de su principal crítico, Platón, las teorías de los sofistas aparecen hoy con una flexibilidad que es altamente positiva. Y, en definitiva, no se puede pasar por alto que la temática que el mismo Platón desarrollaría fue la que iniciaron los sofistas.

\section{Referentes bibliográfícos}

Aristóteles. (1973). Obras, Aguilar, Madrid.

Bowra. C.M. (1976). La Atenas de Pericles, Alianza Editorial, Madrid.

Campillo Iborra y Vegas C. (1976). Sócrates y los sofistas. Valencia.

Cornford, F. (1968). Teoría platónica del conocimiento. Paidós, Buenos Aires.

Guthrie, W. (1982). Los filósofos griegos. Fondo de Cultura Económica, México. Jaeger, W. (1972). Paideia. Fondo de Cultura Económica, México.

Llanos, A. (1969). Los viejos sofistas y el humanismo. Juárez Editor, Buenos Aires.

Mondolfo, R. (1972). Teoría platónica del conocimiento. Losada, Buenos Aires. Platón. (1969). Obras Completas. Aguilar, Madrid.

Platón. (1963). La República, Eudeba, Buenos Aires.

Rodríguez Adrados, F. (1975). La democracia ateniense. Alianza Editorial, Madrid.

Thomson, G. (1975). Los primeros filósofos. Editorial Siglo XX, Buenos Aires. 


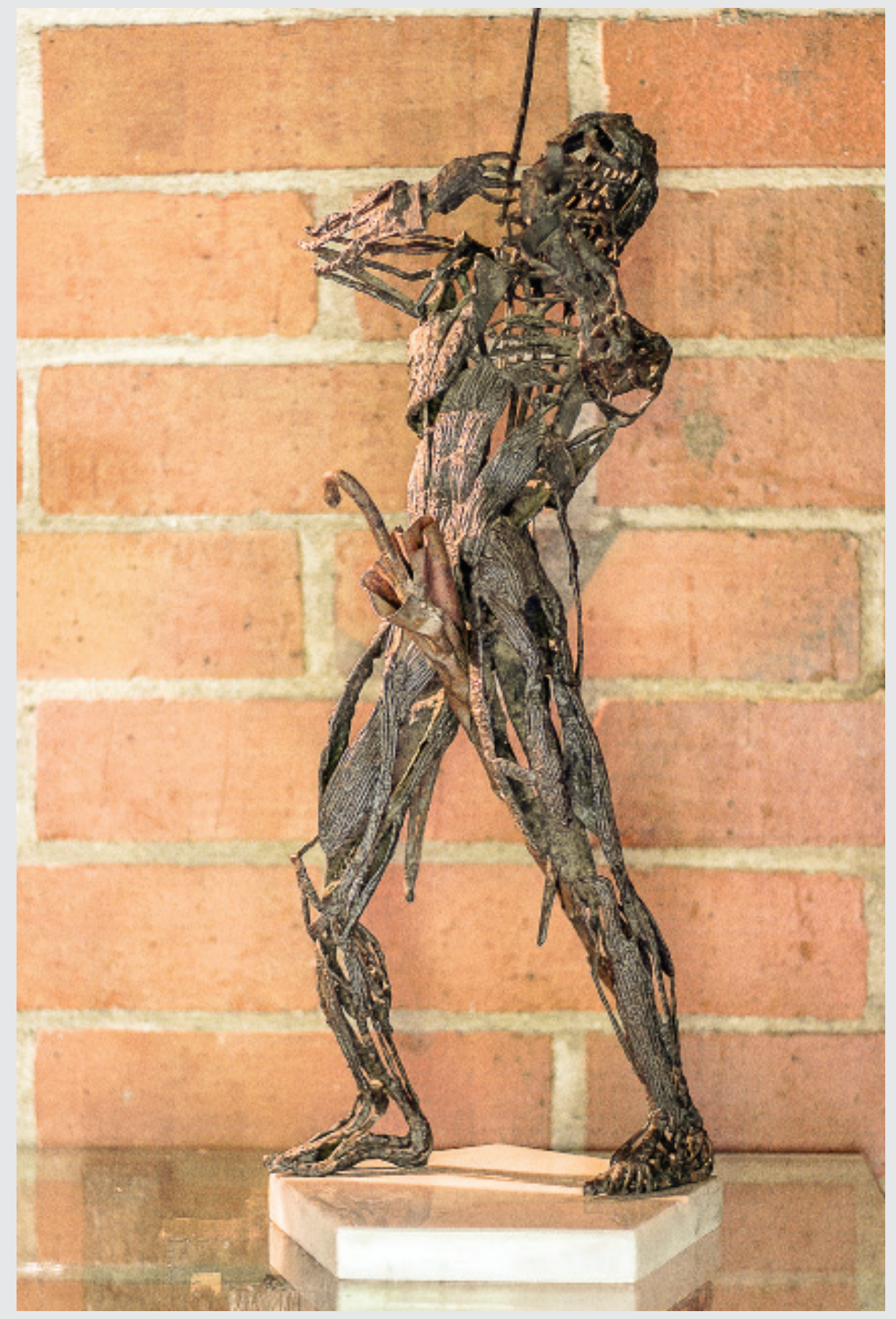

Rubén Martínez Bulnes 